\title{
An Empirical Study of Food Safety, Food Handling, and Food Poisoning Awareness Among Foreign Students in Penang, Malaysia
}

\author{
Kaiser Mahmood $^{\# 1}$, Jamshed Khalid ${ }^{* 2}$, Hanisah Kamilah ${ }^{\# 3}$, Anees Janee Ali ${ }^{* 4}$, Lubowa Muhammad ${ }^{\# 5}$, and \\ Fazilah Ariffin ${ }^{\# 6}$ \\ ${ }^{\#}$ Food Technology Division, School of Industrial Technology, Universiti Sains Malaysia, Penang, 11800, Malaysia \\ *School of Management, Universiti Sains Malaysia, Penang, 11800, Malaysia \\ E-mail: ${ }^{1}$ mba11ameen@gmail.com; ${ }^{2}$ jamshed.jt@gmail.com; ${ }^{3}$ hanisahkamilah@gmail.com; ${ }^{4}$ aneesali15@yahoo.com; ${ }^{5}$ hamedlu@yahoo.com \\ ${ }^{6}$ fazilah@usm.my
}

\begin{abstract}
These foreign students are highly concerned with food safety and food handling knowledge as they are presumably involved in perilous eating behaviours, which exposes them to the risk of foodborne diseases. The present cross-sectional study aimed to evaluate the awareness and practices regarding food safety and food handling among the foreign students of Universiti Sains Malaysia (USM), Penang. A self-administered questionnaire was used to collect demographic information and to assess awareness of food safety and food handling among foreign students. Questionnaires were distributed into five sections that concealed key food safety apprehensions. A total of 328 students received the questionnaires, and $203(61.89 \%)$ responded. Cleanliness of eating tables, food temperature, smoke-free environment and food handler appearance are the key food safety considerations for the respondents. The results showed that a high percentage of male respondents $(57.98 \%)$ experienced food poisoning, and considered food from restaurants is the cause of foodborne diseases. Respondents have utmost awareness about the cleanliness of utensils and kitchen surfaces, hand hygiene, and preclusion of cross-contamination, however, described a poor knowledge concerning the temperature and heat treatment of the food. Good understanding regarding food poisoning symptoms was observed among the respondents, especially in a female group. The outcome revealed that foreign students, irrespective of gender, demonstrated comparable food safety and food handling knowledge. The study laid emphasis on education and training as an optimum way to foster awareness and encourage students' food safety knowledge and practices.
\end{abstract}

Keywords — awareness; food safety; food handling; foodborne diseases; foreign students

\section{INTRODUCTION}

This Food safety is known to be one of the main concern due to its profound impact on the health of the people. Since food trade has enlarged globally, food safety is now treated as a shared apprehension among developed and developing countries. According to the World Health Organization (WHO), approximately 2 million fatal cases occur globally in a year as a result of food poisoning, particularly in the developing countries [1]. In the same vein, Malaysia is also in the list of the countries pretentious by foodborne diseases. In 2007 , more than $50 \%$ of the total food poisoning cases were imputed to inadequate handling by the food handlers in Malaysia [2]. It was reported that the outbreaks of foodborne incidents in Malaysia are mostly contributed by education institutions sharing $43 \%$ of the total [3].

In the economic plan of Malaysia, RMK-9 (Rancangan Malaysia Ke-9), the authority aimed to have 200,000 foreign students from the globe. It was currently reported that the number of foreign students in Malaysia is 135,502. These amounts are from 160 nations, which included those that studying at public and private higher education institutions [4]. Concurrent to this matter, the adjustment of foreign students regarding the knowledge of food safety, food preparation, and handling process is one the major challenges as the number of the foreign students is increasing [5]. Food safety is considered as a critical contributor to physical well-being, depression, and stress [6]. According to WHO, food safety signifies the measures and conditions that are indispensable during the production, preparation, processing, storage, and distribution of food to certify that it is not harmful and wholesome for human consumption [7]. Numerous factors contribute to the growth of foodborne diseases, and among those factors, low level of knowledge about food safety and handling is highly impacting [6], [8]. Some other common food handling issues include; contaminated raw food, insufficient cooking and improper food storage [9].

Food safety and food handling knowledge among students have been studied worldwide. In Turkey, Sanlier [10] reported that more than $50 \%$ students did not become aware 
with the knowledge of checking the internal temperature of food, which is a secure method to estimate that meat is wellcooked and safe to eat. According to Garayoa et al. [11], students with good food hygiene knowledge had reported better practices. Another study revealed a positive correlation between the student's field of study and exposure to food safety information [12]. Students are mainly anxious about food safety practices, which they perceived as a risk to the health and leading to foodborne diseases [10], [11], [13], [14].

Safer food with minimum the least risk of food poisoning requires a better understanding of consumers about food safety knowledge as well. In conjunction with a growing number of foreign students in Malaysia, it is imperative to learn about the challenges on the subject of their adjustment regarding the awareness of food safety, food handling, and food poisoning. At the moment, there is no empirical research has been conducted to assess the food safety awareness among foreign students studying in Malaysia. Therefore, the present study is aimed to investigate the food safety awareness, knowledge, and practices among foreign students studying in Universiti Sains Malaysia (USM), Penang, Malaysia. This study will illuminate the food safety understandings of students and may help to minimize the risks related to food consumption.

\section{MATERIALS AND METHODS}

\section{A. Subject Selection and Population}

A gender-based study was carried out to evaluate the food safety knowledge and awareness among the male and female foreign students from USM, Penang, Malaysia. Subjects of the study were segregated into different age groups and the level of education. All participants, i.e., foreign students voluntarily participated in this study, and face-to-face interaction between researchers and participants was developed through a meeting to describe the purpose, significance, and protocol of the study. Participants were given two weeks to fill out the questionnaires. Two reminders were sent to the participants who did not respond in the given time. The questionnaires considered for analysis were fully completed and received in the allotted time. A total of 328 foreign students took the questionnaires, but 203 $(61.89 \%)$ participated in the present study.

\section{B. Questionnaire}

A questionnaire was constructed according to the preventive measures set by World Health Organization and previous research studies [15], [16], [17]. The questionnaire was divided into six sections. Demographic data included in Section 1 was comprised of age, gender, marital status, nationality, and education level. Section II was about the awareness of food safety, and Section III includes the personal understandings of participants related to food preparation and risks. In Section IV, food handling knowledge was evaluated on the basis of 12 questions. Food handling practices were presented in Section V by using a 3point scale (always, never, infrequently). In the last section (Section VI), knowledge of food poisoning symptoms was investigated.

\section{Statistical Analysis}

Data analysis was conducted using SPSS 19.0 (Chicago, SPSS Inc. USA) for Windows. Data was demonstrated in frequencies (\%), and the independent chi-square test was used to measure the relation between selected variables and gender. The statistically significant $\mathrm{p}$-value was considered less than 0.05 .

\section{RESULTS AND DISCUSSION}

\section{A. Demographic Profile}

The A total number of 203 respondents (as shown in Table 1) including males 119 (58.6\%), and females 84 $(41.4 \%)$, participated in the study. A percentage of 69.9 were single while the rest $(30.1 \%)$ were married. This study targeted foreign students comprising a major proportion of the respondents from Nigeria $(20.2 \%)$ and the remaining were from Thailand $(16.7 \%)$, Pakistan (13.8\%), India (14.3\%), Iran (12.3\%), China (7.9\%), Iraq (7.4\%) and Egypt (7.4\%). In terms of age distribution, the majority of the respondents $(60.1 \%)$ were in the age group of $21-30$. The second major percentage $(22.2 \%)$ of respondents belonged to age group of $31-40$, followed by $13.3 \%$ and $4.4 \%$ for age groups of less than 20 and above 41, respectively. Foreign students investigated in this study were belong to three different levels of education. The highest portion was belonged to Master Degree (43.8\%), followed by Bachelor (30.1\%) and Doctor of Philosophy (26.1\%) (Table 1).

TABLE I

DEMOGRAPHIC PROFILE OF RESPONDENTS

\begin{tabular}{|l|l|l|}
\hline Variable & $\begin{array}{l}\text { Total } \\
\text { amount }\end{array}$ & Percentage (\%) \\
\hline Sex & 119 & 58.6 \\
\hline Male & 84 & 41.4 \\
\hline Female & \multicolumn{2}{|l|}{} \\
\hline Marital status & 69.9 \\
\hline Single & 142 & 30.1 \\
\hline Married & 61 & \\
\hline Age (years) & 27 & 13.3 \\
\hline$<20$ & 122 & 60.1 \\
\hline $21-30$ & 45 & 22.2 \\
\hline $31-40$ & 9 & 4.4 \\
\hline$>41$ & \multicolumn{3}{|l}{} \\
\hline Nationality & 41 & 20.2 \\
\hline Nigerian & 34 & 16.7 \\
\hline Thailand & 28 & 13.8 \\
\hline Pakistani & 29 & 14.3 \\
\hline Indian & 25 & 12.3 \\
\hline Iranian & 16 & 7.9 \\
\hline Chinese & 15 & 7.4 \\
\hline Iraqi & 15 & 7.4 \\
\hline Egyptian & 61 & 30.1 \\
\hline Education level & 89 & 43.8 \\
\hline Bachelor Degree & 53 & 26.1 \\
\hline Master Degree & \\
\hline Ph.D. Degree & \\
\hline
\end{tabular}




\section{B. Food Safety Considerations}

No Gender-based food safety considerations of foreign students are shown in Table 2. The respondents were scrutinized for eight food safety considerations that correlated with the food itself, food handling environment and the food handlers. Based on the data from 203 respondents, it was shown that the majority of the respondents were concerned about the cleanliness of eating table $(96.06 \%)$, smoke-free environment $(94.58 \%)$ and clean eating area $(92.12 \%)$. The least number of participants was apprehensive about food presentation (59.11\%). Astoundingly, $65.52 \%$ respondents signified the importance of food flavour, which is related to the safety of the food. The main food safety concern from the male respondents was the cleanliness of eating table (96.63\%), while they were less agitated with the flavour of the food $(52.94 \%)$. Contrarily, the major concern from the female respondents was the smoke-free environment (97.62\%). However, the presentation of the food is less apprehensive $(65.48 \%)$ for them. A difference in statistically significant value has been noted in the responses of male and female foreign students for food safety considerations; presentation of food, food flavour, food temperature, smoke-free environment and appearance of the food handlers.

TABLE II

GENDER RELATION WITH FOOD SAFETy CONSIDERATIONS

\begin{tabular}{|l|r|r|r|r|r|}
\hline Considerations & \multicolumn{2}{|c|}{ Male } & \multicolumn{2}{c|}{ Female } & $p$-value \\
\hline & \multicolumn{1}{|l|}{ Yes } & \multicolumn{1}{|c|}{ No } & \multicolumn{1}{c|}{ Yes } & \\
\hline Cleanliness of eating tables & $115(96.63 \%)$ & $4(3.37 \%)$ & $80(95.24 \%)$ & $4(4.76 \%)$ & 0.948 \\
\hline Food flavor & $63(52.94 \%)$ & $56(47.06 \%)$ & $70(83.33 \%)$ & $14(16.67 \%)$ & 0.000 \\
\hline Food temperature & $110(92.44 \%)$ & $9(7.56 \%)$ & $67(79.76 \%)$ & $17(20.24 \%)$ & 0.001 \\
\hline Presentation of food & $65(54.62 \%)$ & $54(45.38 \%)$ & $55(65.48 \%)$ & $29(34.52 \%)$ & 0.001 \\
\hline Smoke-free environment & $110(92.44 \%)$ & $9(7.56 \%)$ & $82(97.62 \%)$ & $2(2.38 \%)$ & 0.010 \\
\hline Freshness of food & $105(88.24 \%)$ & $14(11.76 \%)$ & $74(88.10 \%)$ & $10(11.90 \%)$ & 0.330 \\
\hline Clean eating area & $110(92.44 \%)$ & $9(7.56 \%)$ & $77(91.67 \%)$ & $7(8.33 \%)$ & 0.347 \\
\hline $\begin{array}{l}\text { Appearance of food } \\
\text { handlers }\end{array}$ & $115(96.64 \%)$ & $4(3.36 \%)$ & $70(83.33 \%)$ & $14(16.67 \%)$ & 0.000 \\
\hline
\end{tabular}

*Gender-based data presented in frequencies (\%); independent chi-square test conducted to evaluate the association between gender and selected variables.

Cleanliness of eating tables is a key concern for food safety. A number of reports evaluated food safety components based on hygienic conditions of eating environment, i.e., dining table [18], [19]. Similarly, cleanliness of the environment is also an important element to assess the overall food serving conditions. In the present study, eating and environment cleanliness has been taken into consideration by the high percentage response of the participants. Food temperature is another major concern of foreign students regarding food safety considerations. Previous studies by Al-Shabib et al. [20] and Mozaffarian and Rimm [21] illustrated that the desire of the customer to have freshly cooked food to reduce the risk of foodborne pathogens and infections. The findings of the current study demonstrated the correlation between food handler appearance and food safety. It was indicated that the foreign students preferred a well-dressed and clean handler rather than a scruffily dressed one. Our results supported the findings of Adam et al. [19] who illustrated that $82.7 \%$ were apprehensive about the appearance of the food handler. Therefore, neat appearance of food handler is of utmost importance.

\section{Gender Association with Food Poisoning and Food Preparation}

Female participants $(21.43 \%)$ are remarkably higher in percentage than the male participants $(6.72 \%)$ for these questions; daily food preparation or helping in preparation. Only $19.33 \%$ of male respondents were cooking food for several times a week, while the percentage of female respondents was two-fold $(38.10 \%)$. In the response to food poisoning experience, $69 \%$ male and $37 \%$ female stated that they experienced the concerned issue. As presented in Table 3 , male respondents $(73.95 \%)$ are greater in number than female $(60.71 \%)$ in terms of food poisoning knowledge. In the same way, the higher number of male students $(88.24 \%)$ showed their willingness to have more knowledge about food preparation and handling than their female $(70.24 \%)$ counterparts. Moreover, very high numbers of male and female respondents acknowledged the food poisoning perils and considered it as a fatal disease. Furthermore, the majority of the respondents, particularly the male respondents $(p \leq 0.001)$, agreed that food which is cooked at home is much safer than the one that is cooked from restaurants.

The results of the study approved the findings of the previous study by Ovca [17] regarding student preferences to prepare food at home. In food preparation or helping in preparation, female respondents have a higher percentage $(89.27 \%)$ than the male respondents. Male respondents outnumbered their female counterparts in experiencing food poisoning. The findings revealed that food from restaurants is the main cause of poisoning as food safety practices are not followed strictly. Male respondents are more concerned to gain knowledge in preparation and safe handling of food to prevent food poisoning as compared to female respondents. Hence, it is prudent to update the food safety knowledge and practices, as self-efficacy may sometimes mislead and fetch some negative results [22]. 
TABLE III

GENDER ASSOCIATION WITH FOOD POISONING AND FOOD PREPARATION

\begin{tabular}{|c|c|c|c|c|c|}
\hline Questions & Male & $\%$ & Female & $\%$ & $p$-value \\
\hline \multicolumn{5}{|c|}{ How often do you prepare food or help in the preparation of food? } & 0.000 \\
\hline Never & 15 & 12.61 & 9 & 10.71 & \\
\hline Daily & 8 & 6.72 & 18 & 21.43 & \\
\hline Occasionally & 73 & 61.34 & 25 & 29.76 & \\
\hline Several times a week & 23 & 19.33 & 32 & 38.10 & \\
\hline \multicolumn{5}{|c|}{ Have you ever been poisoned by food? } & 0.000 \\
\hline Yes & 69 & 57.98 & 37 & 44.05 & \\
\hline No & 27 & 22.69 & 40 & 47.62 & \\
\hline Don't Know & 23 & 19.33 & 7 & 8.33 & \\
\hline \multicolumn{5}{|c|}{ Food cooked at home or at restaurants causes poisoning. } & 0.001 \\
\hline Restaurant/ Canteen & 111 & 93.28 & 64 & 76.19 & \\
\hline Home/dormitory/hostel & 6 & 5.04 & 6 & 7.14 & \\
\hline Don't know & 2 & 1.68 & 14 & 16.67 & \\
\hline \multicolumn{5}{|c|}{ Food poisoning is dangerous to health. } & 0.604 \\
\hline Yes & 116 & 97.48 & 82 & 97.62 & \\
\hline No & 0 & 0.00 & 1 & 1.19 & \\
\hline Don't know & 3 & 2.52 & 1 & 1.19 & \\
\hline \multicolumn{5}{|c|}{ Knowledge offood poisoning. } & 0.005 \\
\hline Yes & 88 & 73.95 & 51 & 60.71 & \\
\hline No & 16 & 13.45 & 18 & 21.43 & \\
\hline Don't know & 15 & 12.60 & 15 & 17.86 & \\
\hline \multicolumn{5}{|c|}{ Do you want more knowledge on food preparation and handling? } & 0.000 \\
\hline Yes & 105 & 88.24 & 59 & 70.24 & \\
\hline No & 11 & 9.24 & 21 & 25.0 & \\
\hline Don't know & 3 & 2.52 & 4 & 4.76 & \\
\hline
\end{tabular}

*Gender-based data presented in frequencies (\%); independent chi-square test conducted to evaluate the association between gender and variables.

\section{The Knowledge of Food Handling}

The results concerning food handling knowledge and awareness are presented in Table 4. By the total respondents, the majority $(83.74 \%)$ was agreed on the responsibility of the consumers for food safety after purchasing food items. The high number of respondents had a better understanding about the cleanliness of utensils $(91.13 \%)$, and preparation surfaces in a kitchen $(86.20 \%)$. A few female $(11.91 \%)$ and male respondents $(26.05 \%)$ acknowledged keeping cooked and raw food items in the refrigerator. Respondents, particularly female $(\mathrm{p}<0.002)$, disagreed with using only one cloth for drying wet hands while preparing food. Findings depicted that students have good knowledge in terms of food cross-contamination. In the evaluation of food reheating knowledge, male $(63.87 \%)$ and female respondents $(58.33 \%)$ agreed on quick food reheating. Furthermore, the students rated tasting like the best tactic to check whether the food cooking method and time was sufficient. A remarkable percentage of students showed their awareness about refrigerating perishable food items before use. On the other hand, the percentage of females $(22.62 \%)$ was lower than male respondents $(58.82 \%)$, when the suitable temperature of microbial growth was asked about. Moreover, the evaluation of knowledge about food spoilage through damaged food packing indicated that male respondents are more conscious than female counterparts. Likewise, $93.28 \%$ male and $89.29 \%$ female students confirmed that the suitability of food consumption depends on the smell, appearance, and taste. Lastly, food handling awareness about hand washing before handling food was also assessed, and results found statistically significant $(\mathrm{p}<0.022)$ between male and female respondents. As shown in Table 4, the overall score of the male respondents was greater than female respondents regarding food handling knowledge and awareness.

\section{E. Assessment of Food Handling Practices}

The average level of food handling knowledge by respondents found in the present study supported the findings of previous researchers [10], [11], [14]. Foreign students are well-aware with the cleanliness of kitchen surfaces and utensils and hand hygiene. Whereas, poor knowledge was reported regarding the food temperature on the shelf and reheating.

Our results are in agreement with the findings of Osaili et al. [12] who reported that female college students were wellinformed about disinfection procedures and prevention of cross-contamination. WHO reported that $45.6 \%$ cases of foodborne diseases are caused by poor refrigeration, temperature abuse while food preparation and unsuitable storage temperature of recently cooked foods or leftovers [1]. Our findings indicated good knowledge of students about storage, preparation, and cooking of food suggesting less risk of foodborne diseases. 
TABLE IV

GENDER RELATION WITH FOOD HANDLING KNOWLEDGE

\begin{tabular}{|c|c|c|c|c|c|c|c|}
\hline Knowledge of food handling & \multicolumn{3}{|c|}{ Male } & \multicolumn{3}{|c|}{ Female } & $p$-value \\
\hline & Yes & $\mathrm{No}$ & Don't know & Yes & No & Don't know & \\
\hline $\begin{array}{l}\text { Consumer is responsible for } \\
\text { food safety after purchase. }\end{array}$ & $100(84.03 \%)$ & $11(9.24 \%)$ & $8(6.72 \%)$ & $70(83.33 \%)$ & $11(13.10 \%)$ & $3(3.57 \%)$ & 0.252 \\
\hline $\begin{array}{l}\text { All utensils should be cleaned } \\
\text { before preparing food. }\end{array}$ & $110(92.44 \%)$ & $0(0.00 \%)$ & $9(7.56 \%)$ & $75(89.29 \%)$ & $3(3.57 \%)$ & $6(7.14 \%)$ & 0.100 \\
\hline $\begin{array}{l}\text { Cleaning utensils and surfaces } \\
\text { removes dirt, food residues and } \\
\text { microbes. }\end{array}$ & $108(90.76 \%)$ & $3(2.52 \%)$ & $8(6.72 \%)$ & $67(79.76 \%)$ & $4(4.76 \%)$ & $13(15.48 \%)$ & 0.158 \\
\hline $\begin{array}{l}\text { Cooked and uncooked food } \\
\text { should be kept in the same } \\
\text { container of the refrigerator. }\end{array}$ & $31(26.05 \%)$ & $67(56.30 \%)$ & $21(17.65 \%)$ & $10(11.91 \%)$ & $71(84.52 \%)$ & $3(3.57 \%)$ & 0.000 \\
\hline $\begin{array}{l}\text { Do you use only one cloth } \\
\text { during food preparation for } \\
\text { drying wet hands, wiping the } \\
\text { dishes and work bench? }\end{array}$ & $29(24.37 \%)$ & $70(58.82 \%)$ & $20(16.81 \%)$ & $23(27.38 \%)$ & $53(63.10 \%)$ & $8(9.52 \%)$ & 0.002 \\
\hline Do you reheat food quickly? & $76(63.87 \%)$ & $25(21.00 \%)$ & $18(15.13 \%)$ & $49(58.33 \%)$ & $21(25.00 \%)$ & $14(16.67 \%)$ & 0.000 \\
\hline $\begin{array}{l}\text { Tasting is the best method to } \\
\text { check whether cooking was } \\
\text { sufficient. }\end{array}$ & $80(67.22 \%)$ & $18(15.13 \%)$ & $21(17.65 \%)$ & $55(65.48 \%)$ & $25(29.76 \%)$ & $4(4.76 \%)$ & 0.000 \\
\hline $\begin{array}{l}\text { Do you refrigerate purchased } \\
\text { perishable food items (meat, } \\
\text { vegetables) before use? }\end{array}$ & $103(86.56 \%)$ & $9(7.56 \%)$ & $7(5.88 \%)$ & $72(85.71 \%)$ & $4(4.76 \%)$ & $8(9.52 \%)$ & 0.993 \\
\hline $\begin{array}{l}\text { Most suitable temperature for } \\
\text { growth of microorganisms is } \\
30-40^{\circ} \mathrm{C} \text {. }\end{array}$ & $70(58.82 \%)$ & $10(8.40 \%)$ & $39(32.77 \%)$ & $19(22.62 \%)$ & $8(9.52 \%)$ & $57(67.86 \%)$ & 0.000 \\
\hline $\begin{array}{l}\text { Damage in food packing can } \\
\text { cause food spoilage. }\end{array}$ & $89(74.79 \%)$ & $11(9.24 \%)$ & $19(15.97 \%)$ & $57(67.86 \%)$ & $8(9.52 \%)$ & $19(22.62 \%)$ & 0.000 \\
\hline $\begin{array}{l}\text { Food with bad smell, } \\
\text { appearance or taste is } \\
\text { unsuitable for consumption. }\end{array}$ & $111(93.28 \%)$ & $1(0.84 \%)$ & $7(5.88 \%)$ & $75(89.29 \%)$ & $4(4.76 \%)$ & $5(5.95 \%)$ & 0.015 \\
\hline $\begin{array}{l}\text { Hand washing before handling } \\
\text { food reduces the risk of } \\
\text { contamination. }\end{array}$ & $105(88.24 \%)$ & $3(2.52 \%)$ & $11(9.24 \%)$ & $76(90.48 \%)$ & $5(5.95 \%)$ & $3(3.57 \%)$ & 0.022 \\
\hline
\end{tabular}

The assessment of gender association with the practices of food handling is shown in Table 5. The majority of the students are positively concerned about food handling practices, such as $76.35 \%$ students never used food with damaged packaging. Similarly, $77.31 \%$ male and $83.33 \%$ female respondents preferred to wash chopping board or knife before preparation of food. Only very small percentage of male $(14.29 \%)$ and female $(20.24 \%)$ respondents noticed the refrigerator temperature before opening it. Female students outnumbered the male counterparts in response to food preparation with wounds and injuries on hands. It was observed that $57.14 \%$ female had never cooked food in such situation. Surprisingly, less than $50 \%$ of the respondents save the leftovers in the refrigerators after consumption. More than $50 \%$ male respondents infrequently wash dishes with warm water as compared to female respondents (46.43\%) and $77.38 \%$ female respondents always clean the kitchen after food preparation. In the evaluation of expired food items, $76.19 \%$ female respondents avoid expired food items while a somehow similar percentage $(70.59 \%)$ was found for male respondents. Furthermore, in the same vein, female respondents $(89.29 \%)$ are more secured in terms of washing hands before cooking than the male respondents
(79.83\%). Overall, a statistically significant difference $(\mathrm{p}<0.05)$ was observed in the assessment of gender relation with food handling practices (Table 5).

In the findings of the current study, the majority of the students stated that they practiced avoiding the food with damaged packaging. More than 50\% respondents established that unwashed chopping board/knife and food preparation with injuries or bruises are not good practices in food handling. However, still, there was a considerable proportion of the respondents (30-40\%) who occasionally followed the above-mentioned practices which may result in food spoilage leading to foodborne diseases. Another cause of concern was the storage of leftovers, as less than $50 \%$ respondents store leftovers in the refrigerator. Nonetheless, this finding is indifferent than what reported previously by Hapala and Probert [23]. Additionally, findings indicated that $2 / 3^{\text {rd }}$ of the respondents always wash hands prior to food preparation, but the removal of watches and jewellery before cooking is not a common practice for both male and female respondents. In terms of gender distribution, it was found that the female respondents are highly considerate to food handling practices. 
TABLE V

Gender Relation with Assessment of Food Handling Practices

\begin{tabular}{|c|c|c|c|c|c|c|c|}
\hline Knowledge of food handling & \multicolumn{3}{|c|}{ Male } & \multicolumn{3}{|c|}{ Female } & \multirow[t]{2}{*}{$p$-value } \\
\hline & Always & Never & Infrequently & Always & Never & Infrequently & \\
\hline $\begin{array}{l}\text { Do you use food with } \\
\text { damaged packing? }\end{array}$ & $9(7.56 \%)$ & $86(72.27 \%)$ & $24(20.17 \%)$ & $3(3.57 \%)$ & $69(82.14 \%)$ & $12(14.29 \%)$ & 0.029 \\
\hline $\begin{array}{l}\text { Do you use unwashed } \\
\text { chopping board/knife? }\end{array}$ & $8(6.72 \%)$ & $92(77.31 \%)$ & $19(15.97 \%)$ & $5(5.95 \%)$ & $70(83.33 \%)$ & $9(10.71 \%)$ & 0.293 \\
\hline $\begin{array}{l}\text { Do you check the temperature } \\
\text { of the refrigerator before } \\
\text { opening it? }\end{array}$ & $17(14.29 \%)$ & $77(64.71 \%)$ & $25(21.00 \%)$ & $8(9.52 \%)$ & $59(70.24 \%)$ & $17(20.24 \%)$ & 0.139 \\
\hline $\begin{array}{l}\text { Do you prepare food when } \\
\text { you have wounds, bruises or } \\
\text { injuries on hands? }\end{array}$ & $9(7.56 \%)$ & $64(53.78 \%)$ & $46(38.66 \%)$ & $8(9.52 \%)$ & $48(57.14 \%)$ & $28(33.33 \%)$ & 0.137 \\
\hline $\begin{array}{l}\text { Do you save the leftovers in } \\
\text { the refrigerator? }\end{array}$ & $53(44.54 \%)$ & $22(18.49 \%)$ & $44(36.97 \%)$ & $41(48.81 \%)$ & $8(9.52 \%)$ & $35(41.67 \%)$ & 0.333 \\
\hline $\begin{array}{l}\text { Do you wash dishes with } \\
\text { warm water? }\end{array}$ & $37(31.09 \%)$ & $15(12.61 \%)$ & $67(56.30 \%)$ & $39(46.43 \%)$ & $6(7.14 \%)$ & $39(46.43 \%)$ & 0.333 \\
\hline $\begin{array}{l}\text { Do you clean the kitchen } \\
\text { counter and utensils after food } \\
\text { preparation? }\end{array}$ & $64(53.78 \%)$ & $11(9.24 \%)$ & $44(36.98 \%)$ & $65(77.38 \%)$ & $4(4.76 \%)$ & $15(17.86 \%)$ & 0.333 \\
\hline $\begin{array}{l}\text { Do you check the cleanliness } \\
\text { of the utensils before cooking? }\end{array}$ & $84(70.59 \%)$ & $13(10.92 \%)$ & $22(18.49 \%)$ & $71(84.52 \%)$ & $5(5.95 \%)$ & $8(9.52 \%)$ & 0.002 \\
\hline $\begin{array}{l}\text { Do you remove watches, rings } \\
\text { and jewellery before cooking? }\end{array}$ & $54(45.38 \%)$ & $27(22.69 \%)$ & $38(31.93 \%)$ & $48(57.14 \%)$ & $21(25.00 \%)$ & $15(17.86 \%)$ & 0.015 \\
\hline Do you use expired food items & $12(10.08 \%)$ & $84(70.59 \%)$ & $23(19.33 \%)$ & $9(10.71 \%)$ & $64(76.19 \%)$ & $11(13.10 \%)$ & 0.074 \\
\hline $\begin{array}{l}\text { Do you wash hands before } \\
\text { cooking? }\end{array}$ & $95(79.83 \%)$ & $7(5.88 \%)$ & $17(14.29 \%)$ & $75(89.29 \%)$ & $3(3.57 \%)$ & $6(7.14 \%)$ & 0.000 \\
\hline
\end{tabular}

\section{F. Gender Association with Knowledge of Food Poisoning Symptoms}

The present study assessed the knowledge and awareness of food poisoning symptoms in male and female respondents (Fig. 1). The majority of the respondents perceived fatigue, fever, abdominal cramps and diarrhoea as the main symptoms of food poisoning. However, eye pain, headache, hypertension, sweating, and coughing were considered less prevalent symptoms of food poisoning.

Gender-based distribution of main symptoms revealed that fatigue (male respondents, $91.1 \%$; female respondents, $78.5 \%$ ), fever (male respondents, $80 \%$; female respondents, $90.1 \%$ ), abdominal cramps (male respondents, 76.6\%; female respondents, 84\%) and diarrhoea (male respondents, $94.8 \%$; female respondents, 97.5\%) are the major annotations of food poisoning. Overall, the score of female response for knowledge of food poisoning symptoms was greater than the male response, as shown in Fig. 1.

The students, particular females, presented good understandings about major symptoms of food poisoning, such as abdominal cramps, diarrhoea, and fatigue. Similarly, studies [24], [25] strengthen that diarrhoea, abdominal cramps and fatigue are the main outcomes of food poisoning. However, still a number of respondents unable to comprehend the actual signs of food poisoning due to lack of proper knowledge and awareness. Hence, to prevent food poisoning, knowledge and awareness regarding its causes and symptoms should be disseminated among the students.

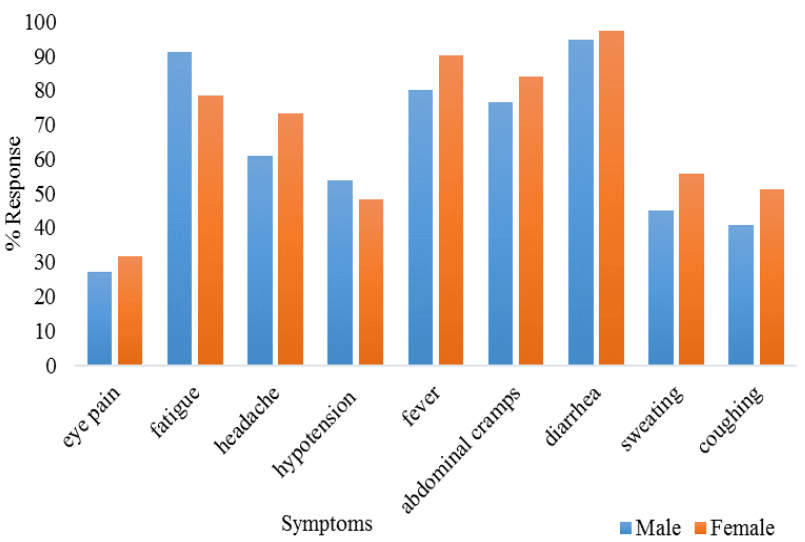

Fig. 1 Evaluation of symptoms of foodborne diseases

\section{CONCLUSIONS}

The findings of the present study demonstrated that better knowledge and awareness is found in the studied group of students. However, still, some students presented a lack of knowledge or practices of food safety in their daily life. In educational and research institutes it is quite easy to improvise food safety knowledge and awareness among students, as education is a great tool to manipulate attitude and behavior. Hence, proper training and awareness programs should be designed and conducted to improve the students' food safety knowledge, awareness and practices. The authorities could play a vital role in the propagation of food safety concepts and practices among students, particularly the foreign students. 


\section{ACKNOWLEDGMENT}

One of the authors (Kaiser Mahmood) is grateful to the USM Global Fellowship Scheme, Universiti Sains Malaysia, Penang, Malaysia.

\section{CONFLICT OF INTEREST}

Authors declare no conflict of interest.

\section{REFERENCES}

[1] World Health Organization (WHO), "Food Safety", Geneva, Switzerland, 2015 [Online]. Available: http://www.who.int/mediacentre/factsheets/fs399/en/

[2] Ministry of Health (MOH), “Annual Report 2007," MOH: Putrajaya, Malaysia, 2007.

[3] Ministry of Health (MOH), "The National Level 2014 Clean, Safe and Healthy Canteen Award; Department of Food Safety and Food Quality," MOH: Putrajaya, Malaysia. 2014.

[4] The Sundaily, 2015. Malaysia has one of highest proportions of international students pursuing higher education [Online]. Available: http://www.thesundaily.my/news/1314991 (Retrieved at 07-05-2017).

[5] Z. Mahmud, S. Amat, S. Rahman, and N.M. Ishak, "Challenges for International Students in Malaysia: Culture, Climate and Care," Procedia: Social and Behavioral Sciences, vol. 7, pp. 289-293, 2010.

[6] P. Rozin, C. Fischler, S. Imada, A. Sarubin, and A. Wrzesniewski, "Attitude to food and the role of food in life in the USA, Japan, Flemish Belgium and France: possible implications for the diethealth debate," Appetite, vol. 33, pp. 163-180, 1999.

[7] World Health Organization (WHO), "The Role of Food Safety in Health and Development, Technical Report Series, 705", Geneva, 1984

[8] L. Sharif, M. Obaidat, and M. Al-Dalalah, "Food Hygiene Knowledge, Attitudes and Practices of the Food Handlers in the Military Hospitals," Food Nutr. Sci., vol. 4 (3), pp. 245-251, 2013.

[9] L. Medeiros, V. Hillers, C. Gang, V. Bergmann, P. Kendall, and M. Schroeder, "Design and development of food safety knowledge and attitude scales for consumer food safety education," J. Am. Diet. Assoc., vol. 104 (11), pp. 1671-1677, 2004.

[10] N. Sanlier, "The knowledge and practice of food safety by young and adult consumers," Food Control, vol. 20, pp. 538-542, 2009.

[11] R. Garayoa, M. Cordoba, I. García-Jalon, A. Sanchez-Villegas, and A.I. Vitas, "Relationship between consumer food safety knowledge and reported behavior among students from health sciences in one region of Spain," J. Food Prot., vol. 68, pp. 2631-2636, 2005.

[12] T.M. Osaili, B.A. Obeidat, D.O.A. Jamous, and H.A. Bawadi, "Food safety knowledge and practices among college female students in north of Jordan," Food Control, vol. 22, pp. 269-276, 2011.

[13] C. Byrd-Bredbenner, J. Maurer, V. Wheatley, D. Schaffner, C. Bruhn, and L. Blalock, "Food safety self-reported behaviors and cognitions of young adults: results of a national study," J. Food Prot., vol. 70, pp. 1917-1926, 2007.

[14] L. Sharif, and T. Al-Malki, "Knowledge, attitude and practice of Taif University students on food poisoning," Food Control, vol. 21(1), pp. 55-60, 2010.

[15] World Health Organization (WHO), "Five keys to safer food manual", WHO Department of Food Safety, Zoonoses and Foodborne Diseases, 2006 [Online]. Available: http://www.who.int/entity/foodsafety/publications/consumer/manual _keys.pdf Accessed 26.06.15.

[16] W.Y. Low, R. Jani, H.A. Halim, A.A. Alias, and F.M. Moy, "Determinants of food hygiene knowledge among youths: A crosssectional online study," Food Control, vol. 59, pp. 88-93, 2016.

[17] A. Ovca, M. Jevsnik, and P. Raspor, "Food safety awareness, knowledge, and practices among students in Slovenia," Food Control, vol. 42, pp. 144-151, 2014.

[18] M. Kidd, "Food safety- consumer concerns," Nutr. Food Sci., vol $30(2)$, pp. 53-55, 2000.

[19] I. Adam, S.E. Hiamey, and E.A. Afenyo, "Students' food safety concerns and choice of eating place in Ghana," Food Control, vol. 43, pp. 135-141, 2014.

[20] N.A. Al-Shabib, F.M. Husain, and J.M. Khan, "Study on food safety concerns, knowledge and practices among university students in Saudi Arabia," Food Control, vol. 73, pp. 202-208, 2017.

[21] D. Mozaffarian, and E.B. Rimm, "Fish intake, contaminants, and human health: Evaluating the risk and the benefits," J. Am. Med. Assoc., vol. 296(15), pp. 1885-1899, 2006.

[22] B.A. Mullan, C. Wong, and E.J. Kothe, "Predicting adolescents' safe food handling using an extended theory of planned behavior," Food Control, vol. 31(2), pp. 454-460, 2013

[23] I. Haapala, and C. Probart, "Food safety, perceptions and behaviours among middle school students," J. Nutr. Educ. Behav., vol. 36, pp. 71-76, 2004.

[24] Y. Le Loir, F. Baron, and M. Gautier, "Staphylococcus aureus and food poisoning," Genet. Mol. Res., vol. 2 (1), pp. 63-76, 2003.

[25] M.A. Argudín, M.C. Mendoza, and M.R. Rodicio, "Food poisoning and Staphylococcus aureus enterotoxins," Toxins, vol. 2 (7), pp. 1751-1773, 2010 